\title{
Avaliação da cavidade nasal de camundongos submetidos à exposição ao herbicida ácido 2,4-diclorofenoxiacético
}

\author{
Evaluation of the nasal cavity mice submitted to the inhalation exposure to \\ the herbicide 2,4- dichlorophenoxyacetic acid
}

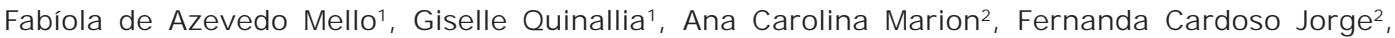
Laura Monico Marinelli ${ }^{2}$, Ana Karina Marques Salge ${ }^{3}$, Marcela de Andrade Bernal Fagiani ${ }^{4}$, Edson Assunção Mareco ${ }^{5}$, Ana Paula Alves Favareto ${ }^{5}$, Renata Calciolari Rossi e Silva ${ }^{5}$

\begin{abstract}
RESUMO
No último ano, o Brasil apresentou um aumento de $190 \%$ na utilização de agrotóxicos, o que implica em um grave problema de saúde pública. O ácido 2,4-diclorofenoxiacético possui classificação toxicológica I (extremamente tóxico) e por ser muito volátil, favorece a contaminação de solos, águas, animais e seres humanos.

Modelo do estudo: Estudo Experimental.

Objetivo: Analisar o infiltrado inflamatório de camundongos submetidos à nebulização aguda ao herbicida ácido 2,4-diclorofenoxiacético, em diferentes intervalos de tempo e concentrações.

Métodos: Foram utilizados 80 camundongos Swiss machos divididos em quatro grupos $(n=20)$ : salina, baixa $\left(3,71 \times 10^{-3}\right.$ gramas de ingrediente ativo por hectare), média $\left(6,19 \times 10^{-3}\right.$ gramas de ingrediente ativo por hectare) e alta concentração $\left(9,28 \times 10^{-3}\right.$ gramas de ingrediente ativo por hectare). Todos os animais foram expostos às nebulizações preconizadas para cada grupo por 15 minutos, em diferentes intervalos de tempo: 24, 48, 72 e 192 horas. O protocolo de exposição contou com duas caixas ligadas a um nebulizador ultrassônico e o vestíbulo nasal de cada animal foi retirado após a eutanásia, para a análise histológica.

Resultados: A contagem de mastócitos apresentou valores significativamente aumentados no grupo alta concentração, no intervalo de tempo de 48 horas, quando comparado ao de 24 horas. Conclusão: Os resultados mostraram que a exposição aguda ao herbicida ácido 2,4-diclorofenoxiacético aumenta a produção de mastócitos na cavidade nasal de animais expostos a altas concentrações, e que podem estar relacionados ao surgimento de reações alérgicas.
\end{abstract}

Palavras-chave: Ácido 2,4-Diclorofenoxiacético. Inflamação. Mastócitos.

1. Pós-graduação Strictu Sensu em Meio Ambiente e Desenvolvimento Regional, Universidade do Oeste Paulista (UNOESTE), Presidente Prudente, SP - Brasil.

2. Faculdade de Medicina, UNOESTE.

3. Faculdade de Enfermagem, Doutorado em Ciências da Saúde, Universidade Federal de Goiás, Brasil.

4. Pós-Graduação Strictu Sensu em Ciência Animal, UNOESTE.

5. Docentes do Programa de Pós-graduação Strictu Sensu em Meio Ambiente e Desenvolvimento Regional, UNOESTE.
CORRESPONDÊNCIA: Fabiola de Azevedo Mello Universidade do Oeste Paulista, Mestrado em Meio Ambiente e Desenvolvimento Regional (MMADRE). Rodovia Raposo Tavares, Km 572 - Bairro Limoeiro. 19067-175 - Presidente Prudente, SP - Brasil. fabiola-azevedo@hotmail.com

Recebido em 22/01/2018 Aprovado em 31/10/2018 


\begin{abstract}
In the last year, Brazil presented a $190 \%$ increase in the use of agrochemicals, which implies a serious public health problem. 2,4-Dichlorophenoxyacetic acid has toxicological classification I (extremely toxic) and because it is very volatile, it favors the contamination of soils, water, animals and humans.

Study model: Experimental study. Objective: To analyze the inflammatory infiltrate of mice submitted to acute nebulization to the 2.4-dichlorophenoxyacetic acid herbicide at different time intervals and concentrations.

Methods: Eighty Swiss male mice were divided into four groups $(n=20)$ : saline, low $(3.71 \times 10-3$ grams of active ingredient per hectare), medium ( $6.19 \times 10-3$ grams of active ingredient per hectare) and high concentration (9.28 $\times 10-3$ grams of active ingredient per hectare). All animals were exposed to the nebulizations proposed for each group, for 15 minutes, at different time intervals: 24, 48, 72 and 192 hours. The exposure protocol had two boxes attached to an ultrasonic nebulizer and the nasal vestibule of each animal was removed after euthanasia for histological analysis.

Results: The mast cell count showed significantly increased values in the high concentration group, in the time interval of 48 hours, when compared to the 24-hour period.

Conclusion: The results showed that the acute exposure to the herbicide 2,4-dichlorophenoxyacetic acid increases the production of mast cells in the nasal cavity of animals exposed to high concentrations, which may be related to the appearance of allergic reactions.
\end{abstract}

Keywords: 2,4-Dichlorophenoxyacetic Acid. Inflammation. Mast cells.

\section{INTRODUÇÃO}

De acordo com os relatórios do Instituto Brasileiro do Meio Ambiente (IBAMA) entre 2009 e 2012, o herbicida ácido 2,4-diclorofenoxiacético $(2,4-D)$ se posicionou entre o terceiro e quarto ingrediente ativo presente na maioria dos herbicidas vendidos no Brasil, e que após o ano de 2013, este passou a ser o segundo composto ativo mais vendido no país. ${ }^{1}$

O ácido 2,4-D é um herbicida utilizado principalmente em culturas de folhas largas, cereais e algumas pastagens, o qual tem potencial para contaminar águas subterrâneas e possui classificação toxicológica do tipo I, que significa extrema toxicidade. É um produto muito volátil, que pode sofrer influência do vento, percorrendo quilômetros de distância dependendo da época do ano em que é utilizado, fato este que favorece a contaminação de solos, águas, animais e seres humanos. ${ }^{2}$

A utilização de agrotóxicos em larga escala tem sido relatada, sendo que o Brasil apresentou um aumento no consumo destes produtos em $190 \%$, o que implica em um grave problema de saúde pública, salientando que os danos causados à saúde humana são classificados em médio e longo prazo. ${ }^{3}$

São considerados desreguladores endócrinos (encontrados no solo, água e tecido adiposo materno) e atingem o feto em sua vida intrauterina, além disso, na população geral, provocam intoxicações agudas e crônicas, problemas reprodutores, irritações cutâneas e pode levar à morte. $^{3}$

Segundo dados da Organização Panamericana da Saúde (OPAS) ${ }^{4}$, a classe dos agrotóxicos à qual pertence o 2,4-D, em humanos, é facilmente absorvida pelo trato digestivo, respiratório ou até mesmo pela pele, possuindo ação tóxica à longo prazo, além disso, pode causar irritação aos olhos, mucosas, bem como alergias na pele, asma, neuropatias (ação na bainha de mielina, causando sua desorganização e rompimento dos axônios). São relatadas em intoxicações agudas: formigamento nas pálpebras e lábios, irritação das conjuntivas e mucosas e espirros. Já na intoxicação crônica, foram relatados: coceira intensa, manchas na pele, secreção e obstrução respiratória, excitação e crises convulsivas. 
Dentre a população geral, a exposição aos agrotóxicos atingem diferentes parcelas da população, em diferentes concentrações, que vão desde os trabalhadores que manipulam diretamente estes produtos, moradores da área rural e urbana e consumidores de alimentos. ${ }^{5}$

Assim sendo, no presente estudo, utilizouse o herbicida 2,4-D em decorrência de sua grande utilização no Oeste do Estado de São Paulo, na cultura da cana-de-açúcar, além de seu crescente uso de forma indiscriminada em diversas regiões do planeta. Para isso, foi utilizada sua dose de exposição real no campo, de acordo com a bula do agroquímico, com o intuito de observar as alterações em decorrência de sua inalação.

O objetivo do estudo foi analisar o infiltrado inflamatório dos camundongos submetidos à nebulização ao herbicida ácido 2,4-diclorofenoxiacético, em diferentes intervalos de tempo e concentrações.

\section{MATERIAL E MÉTODOS}

\section{Aspectos de natureza ética}

O presente estudo foi aprovado pelo Comitê de Ética no Uso de Animais (CEUA) da Universidade do Oeste Paulista (UNOESTE), Presidente Prudente, São Paulo, Brasil, pelo protocolo de número 2563.

\section{Caracterização da amostra}

Oitenta camundongos Swiss adultos machos ( 30 - 45g) foram fornecidos pelo Biotério Central da UNOESTE e alojados no Biotério Experimental da mesma Universidade. Durante o experimento, os animais foram alojados em gaiolas de polipropileno $(30 \mathrm{~cm} \times 16 \mathrm{~cm} \times 19 \mathrm{~cm}$ ) com cama de maravalha e mantidos na mesma sala sob temperatura controlada $\left(22 \pm 2^{\circ} \mathrm{C}\right)$ e condições de iluminação (fotoperíodo de $12 \mathrm{~L}$ e $12 \mathrm{D}$, em que $\mathrm{L}$ corresponde ao período de luz e $\mathrm{D}$ ao período escuro). A água filtrada e a ração comercial (Supralab ${ }^{\circledR}$, Alisul, Brazil) foram ad libitum.

\section{Delineamento experimental}

Os camundongos foram pesados e distribuídos aleatoriamente em quarto grupos experimentais ( $n=20$ animais por grupo):
- Grupo Salina (GS): Exposição a uma névoa de solução salina $(\mathrm{NaCl})$ a $0,9 \%$;

- Grupo Baixa Concentração (GBC): Exposição a uma névoa de solução de 2,4-D, contendo 3,71 $\times 10^{-3}$ gramas de ingrediente ativo por hectare (g.i.a/ha);

- Grupo Média Concentração (GMC): Exposição a uma névoa de solução de 2,4-D, contendo 6,19 $\times 10^{-3}$ gramas de ingrediente ativo por hectare (g.i.a/ha);

- Grupo Alta Concentração (GAC): Exposição a uma névoa de solução de 2,4-D, contendo 9,28 $\times 10^{-3}$ gramas de ingrediente ativo por hectare (g.i.a/ha).

As diferentes doses do herbicida, em cada grupo, basearam-se na recomendação do fabricante para o uso agrícola do 2,4-D ${ }^{\circledR}$ (Formulação comercial, 67,0\% m/v, Nortox, Paraná, Brasil) e adaptado ao tamanho da câmara de exposição.

Os animais de todos os grupos foram expostos a aerossolização durante 15 minutos, em diferentes intervalos de tempo: 24, 48, 72 e 192 horas. Para isso, foram utilizadas duas câmaras (32 × $24 \times 32 \mathrm{~cm}$ ) conectadas ao nebulizador ultrassônico (Pulmosonic Star ${ }^{\circledR}$ ). Diferentes concentrações do herbicida foram diluídas em $10 \mathrm{ml}$ de solução salina a $0,9 \%$ (Figura 1 ).

No primeiro dia de exposição, 80 camundongos foram expostos a aerossolização com a substância/dose especificada para cada grupo (solução salina ou herbicida). Após 24 horas, 20 animais foram anestesiados intraperitonealmente ( $100 \mathrm{mg} / \mathrm{Kg}$ de tiopental sódico) e eutanaseados por exsanguinação, para a coleta do epitélio nasal. Após 48 horas, 20 animais (que receberam a segunda aerossolização) foram submetidos à eutanásia. Outros 20 animais (que receberam a terceira aerossolização) foram sacrificados após 72 horas. Finalmente, após 192 horas, os 20 animais restantes também foram eutanaseados. 0 peso corporal dos camundongos foi registrado antes da eutanásia.

\section{Coleta e análise do vestíbulo nasal}

Após a eutanásia, o vestíbulo nasal de cada camundongo foi coletado para análise histológica sob microscopia óptica. O tecido foi fixado em formaldeído a 10\% durante 24 horas. As peças 


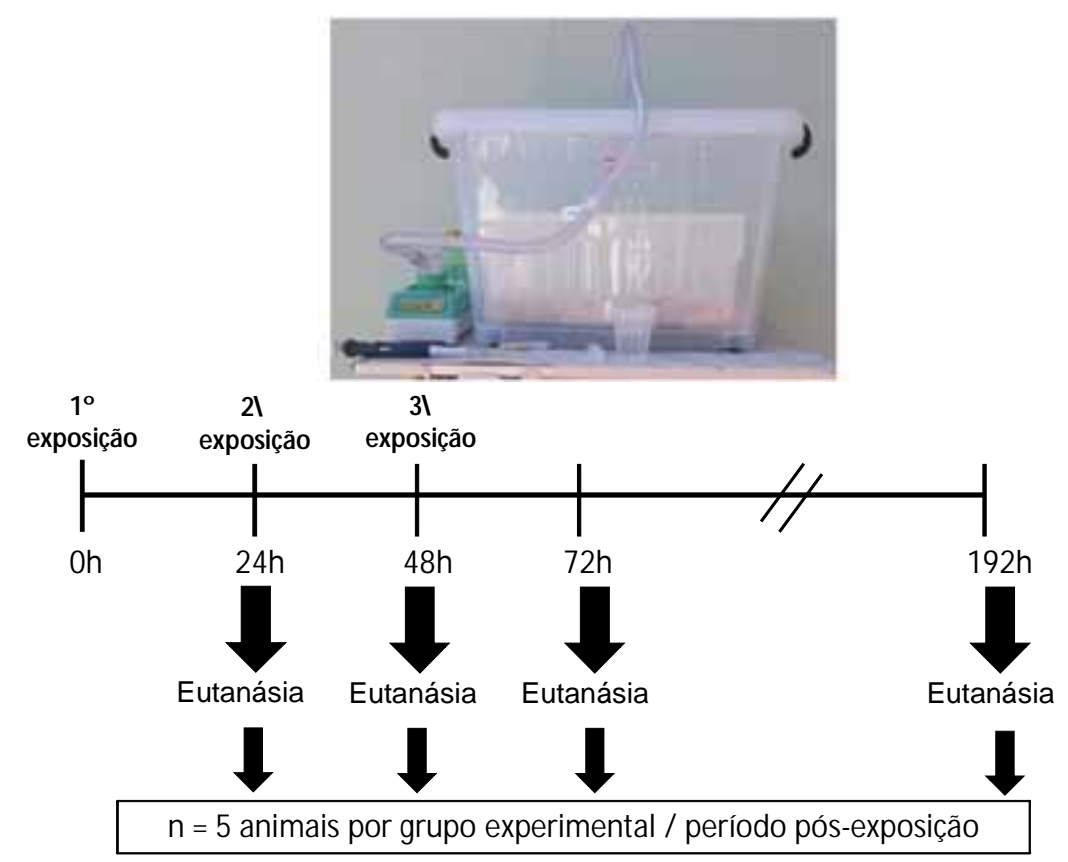

Figura 1: Desenho experimental.

foram incorporadas em cera de parafina e seccionadas a 5ìm ( 10 cortes seriados no plano sagital). As secções de estudo (derme e epiderme) foram coradas com hematoxilina e eosina (HE) para a quantificação de leucócitos totais e azul de toluidina para a quantificação de mastócitos.

Posteriormente, foram capturadas as imagens em microscópio com câmera acoplada (Leica ICC50 HD) para análise morfométrica. Os mastócitos presentes na lâmina própria, em toda a extensão do corte, foram quantificados usando o software Image-Pro Plus ${ }^{\circledR}$ (Versão 7.0, Media Cybernetics, Silver Spring, MD, USA).

A avaliação semi-quantitativa do infiltrado inflamatório foi realizada de acordo com um sistema. Este sistema classifica o infiltrado em uma pontuação de 1 a 3: 1 (áreas ocasionais de inflamação); 2 (inflamação na maioria das áreas, cercada por uma fina camada de células) e 3 (áreas mais inflamadas e cercadas por uma espessa camada de células). ${ }^{6}$ As análises foram realizadas de forma cega.

\section{Análise Estatística}

Inicialmente, verificou-se a normalidade da distribuição dos valores. Para a análise de nor- malidade foi utilizado o pacote estatístico ShapiroWilk disponível no programa R (versão 3.2.3). Para a análise estatística dos dados, considerou-se a presença de dois fatores (Tempo x Concentração). Neste sentido, foi utilizado o teste estatístico de análise de variância de dois fatores (Two-way Anova), disponível no programa estatístico Graphpad Prism (Versão 5.0). Foram considerados estatisticamente diferentes os resultados que apresentaram $\mathrm{p}<0,05$.

\section{RESULTADOS}

A Tabela 1 apresenta a média e o desvio padrão (DP) do peso corpóreo dos camundongos submetidos à nebulização ao $\mathrm{NaCl}$ e ao herbicida 2,4-D, em diferentes concentrações e intervalos de exposição. Não houve diferença significativa entre os grupos.

No presente estudo, não foram verificadas diferenças significativas em relação à avaliação do infiltrado inflamatório e a área da mucosa nasal dos camundongos. Foi analisada a influência do herbicida 2,4-D sobre o possível surgimento de reações alérgicas e observou-se que a média de mastócitos presentes na mucosa dos animais 
apresentou valores significativamente aumentados $(p<0,05)$ no GAC, no intervalo de tempo de 48 horas, quando comparado ao de 24 horas (Figuras 2 e 3 ).

\section{DISCUSSÃO}

Apesar de alguns estudos indicarem que 0 herbicida 2,4-D pode reduzir o peso corpóreo de roedores, devido a diminuição do consumo de alimentos e de água, ${ }^{7,8}$ no presente estudo este parâmetro não foi afetado, em decorrência ao curto período de exposição.
A exposição oral de ratos machos ao 2,4-D pode levar à redução do peso corpóreo após 24 dias de exposição. ${ }^{9}$ Domingues $(2007)^{10}$ realizou um estudo com ratos Wistar que foram expostos ao Diuron em doses repetidas (exposição aguda e sub-crônica) em altas concentrações e observou a diminuição do peso corpóreo em decorrência da redução significativa do consumo de ração pelos animais.

Nosso estudo corrobora com um estudo em que ratos foram expostos a diferentes pesticidas, sendo possível observar o aumento da liberação de histamina, em decorrência do aumento de

Tabela 1

Comparação do peso corpóreo, média e desvio padrão dos modelos experimentais submetidos à exposição ao $\mathrm{NaCl}$ e ao o herbicida 2,4-D.

\begin{tabular}{|c|c|c|c|c|c|c|c|c|}
\hline & \multicolumn{2}{|c|}{$24 \mathrm{~h}$} & \multicolumn{2}{|c|}{$48 \mathrm{~h}$} & \multicolumn{2}{|c|}{$72 \mathrm{~h}$} & \multicolumn{2}{|c|}{$192 \mathrm{~h}$} \\
\hline & Antes & Depois & Antes & Depois & Antes & Depois & Antes & Depois \\
\hline & Média \pm DP & Média \pm DP & & Média \pm DP & Média \pm DP & Média \pm DP & Média $\pm \mathrm{DP}$ & Média $\pm \mathrm{DP}$ \\
\hline Salina & $36,3 \pm 5,5$ & $37,1 \pm 5,9$ & $32,3 \pm 3,4$ & $32,9 \pm 3,3$ & $32,1 \pm 5,8$ & $34,6 \pm 5,0$ & $40,0 \pm 6,1$ & $44,1 \pm 4,6$ \\
\hline GBC & $38,0 \pm 7,0$ & $39,2 \pm 7,2$ & $37,9 \pm 3,1$ & $39,9 \pm 3,0$ & $42,3 \pm 3,2$ & $44,4 \pm 3,5$ & $41,5 \pm 1,9$ & $44,9 \pm 2,1$ \\
\hline GMC & $42,3 \pm 4,5$ & $43,5 \pm 4,2$ & $42,0 \pm 1,5$ & $43,9 \pm 2,2$ & $41,9 \pm 5,0$ & $43,3 \pm 5,0$ & $40,4 \pm 6,1$ & $42,2 \pm 4,8$ \\
\hline GAC & $39,0 \pm 7,1$ & $39,4 \pm 7,0$ & $34,0 \pm 5,0$ & $35,3 \pm 5,6$ & $39,7 \pm 3,6$ & $42,2 \pm 3,2$ & $39,6 \pm 2,3$ & $41,8 \pm 2,1$ \\
\hline
\end{tabular}

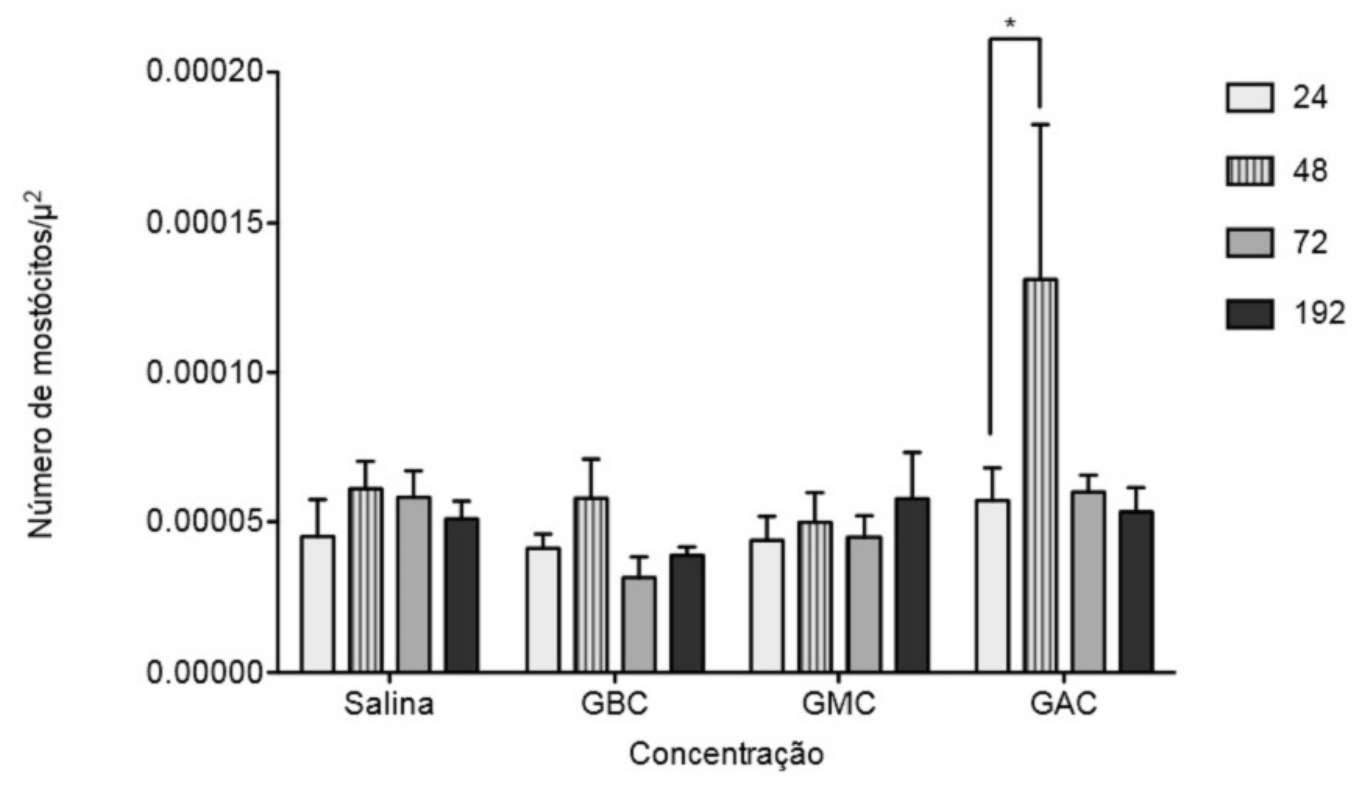

Figura 2: Média de mastócitos presentes na mucosa nasal dos camundongos submetidos à nebulização ao $\mathrm{NaCl}$ e ao herbicida 2,4-D. 


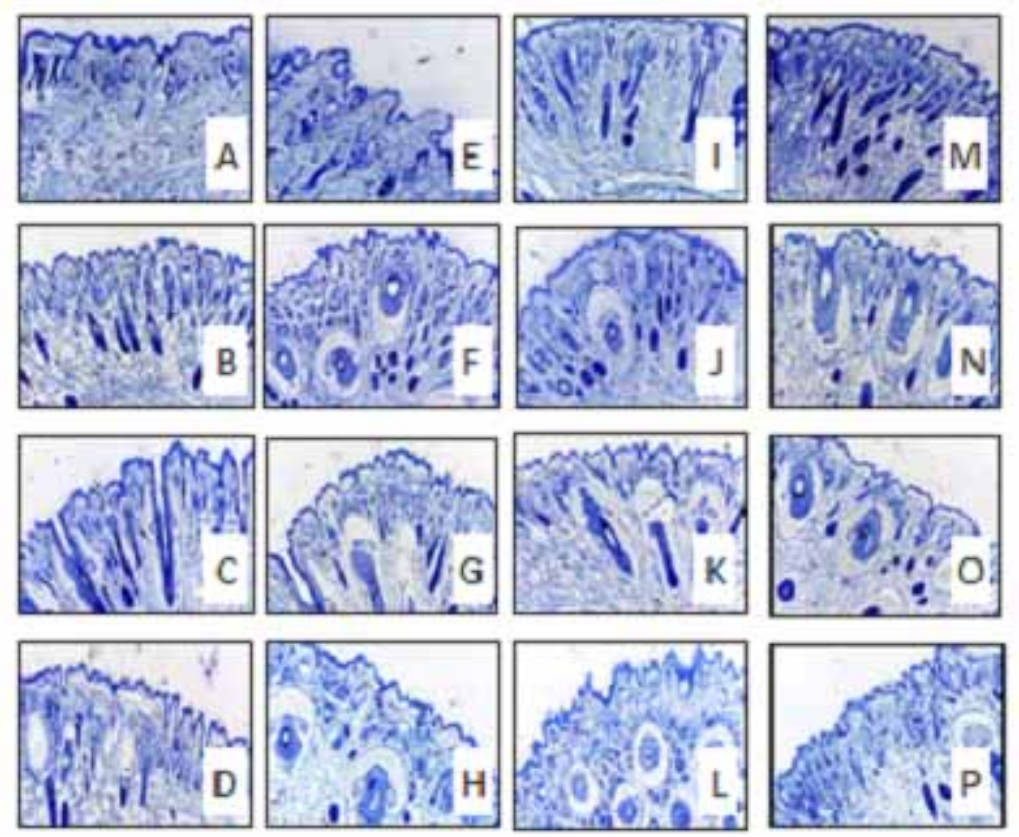

Figura 3: Cortes histológicos da mucosa nasal, para quantificação de mastócitos, em camundongos submetidos à nebulização ao NaCl e ao herbicida 2,4-D.

Em (A, B, C e D) GC exposto ao NaCl nos intervalos de 24 48, 72 e 192 horas, respectivamente (Azul de toluidina, 100x); em (F, G, e H) GBD exposto ao herbicida 2,4-D nos intervalos de 24 48, 72 e 192 horas, respectivamente (Azul de toluidina, 100x); em (I, J, K e L) GDI exposto ao herbicida 2,4-D nos intervalos de 24 48, 72 e 192 horas, respectivamente (Azul de toluidina, 100x) e em (M, N, O e P) GAD exposto ao herbicida 2,4-D nos intervalos de 24 48, 72 e 192 horas, respectivamente (Azul de toluidina, 100x).

mastócitos, ${ }^{11}$ e que podem estar relacionados ao desenvolvimento de reações alérgicas.

Han et al. (2007) ${ }^{12}$ realizaram um estudo com o inseticida Endossulfan, em culturas de macrófagos de camundongos, e observaram o aumento da produção de citocinas pró-inflamatórias e óxido nítrico de maneira dose-dependente. Sato et al. (1997) ${ }^{11}$ concluíram que os organofosforados (Diazinon e Fenitrotion) aumentam significativamente a liberação de histamina em mastócitos de ratos e sugerem que esses agrotóxicos podem, consequentemente, intensificar o surgimento de reações alérgicas.

Observou-se que no GAC no intervalo de tempo de 192 horas, não houve alterações estatisticamente significantes, diferente do que foi observado no mesmo grupo o intervalo de tempo de 72 horas, quando comparado ao de 24 horas. Por esse motivo, as alterações podem estar relacionadas à dose do herbicida, mas não ao tempo de exposição a ele.
Kumar et al. (2014) 13 induziram camundongos a inalação de amostras de ar rico em glifosato, que foram coletadas de fazendo durante a pulverização do herbicida. De acordo com os autores, foi possível observar inflamação nas vias aéreas dos animais, durante curtos e longos períodos de exposição.

\section{Conclusões}

Devido ao elevado consumo de agrotóxicos no mundo, inclusive no Brasil, são enormes os riscos de contaminação de pessoas que são expostas diariamente a essas substâncias. Os resultados mostraram que a exposição aguda ao herbicida ácido 2,4-diclorofenoxiacético aumenta a produção de mastócitos na cavidade nasal de animais expostos a altas concentrações, e que podem estar relacionados ao surgimento de reações alérgicas. Por isso, é necessária a realização de pesquisas adicionais para que essa hipótese seja confirmada. 


\section{REFERÊNCIAS}

1. IBAMA. Boletins 2009-2014: vendas de ingredientes ativos por UF. Brasília: MMA, 2016.

2. Leão MB. Avaliação dos efeitos da associação dos herbicidas 2,4-D e picloram sobre parâmetros de toxicidade em Drosophila melanogaster. [Trabalho de Conclusão de Curso], Caçapava do Sul: Faculdade de Engenharia Ambiental e Sanitária da Universidade Federal do Pampa, Brasil; 2017.

3. Lidiane Silva Dutra, Aldo Pacheco Ferreira. Malformações congênitas em regiões de monocultivo no estado de Minas Gerais, Brasil. Medicina - Ribeirão Preto [internet]. 2017 Out [citado 2018 Jul 04]; 50 (5): 285-296. Disponível em: http:// www. revistas.usp.br/rmrp/article/view/143186 http:/ /dx.doi.org/10.11606/issn.2176-7262.v50i5p285296

4. OPAS (Organização Pan-Americana da Saúde). Ministério da Saúde do Brasil. Secretaria de Vigilância Sanitária. Manual de vigilância de populações expostas a agrotóxicos. Brasília, DF; 1996.

5. Rigotto RM, Aguiar ACP. Invisibilidade ou invisibilização dos efeitos crônicos dos agrotóxicos à saúde? Desafios à ciência e às políticas públicas. In: Observatório Internacional de Capacidades Humanas, Desenvolvimento e Políticas Públicas: estudos e análises 2. Roberto Passos Nogueira et al. Brasília, DF, UnB/ObservaRH/Nesp. Fiocruz/Nethis. 2015.

6. Carnieli DS, Yoshioka E, Silva LFF, Lanças T, Arantes FM, Perini A, Martins MA, Saldiva PHN, Dolhnikoff M, Mauad T. Inflammation and remodeling in infantile, juvenile and adult allergic sensitized mice. Pediatr. Pulmonol. [internet] 2011 Jul [citado 2018 Jul 05]; 46 (7): 650-665. Disponível em: https:// www.ncbi.nlm.nih.gov/pubmed/21360835 10.1002/ ppul. 21436

7. Tayeb W, Nakbi A, Trabelsi M, Attia N, Miled A, Hammami M. Hepatotoxicity induced by sub-acute exposure of rats to 2,4-Dichlorophenoxyacetic acid based herbicide "désormonelourd". J. Hazard. Mater. [internet] 2010 Ago [citado 2018 Jul 05]; 180 (1-3): 225-233. Disponível em: https:// www.ncbi.nlm.nih.gov/pubmed/20447766 10.1016/ j.jhazmat.2010.04.018
8. AlefTroudi, MadihaSefi, Ibtissem Ben Amara, SoudaniNejila, Ahmed Hakim, Khaled MounirZeghal, TahiaBoudawara, NajibaZeghal. Oxidative damage in bone and erythrocytes of suckling rats exposed to 2,4-dichlorophenoxyacetic acid. Pestic. Biochem. Physiol. [internet] 2012 Set [citado 2018 Jul 05]; 104 (1): 19-27. Disponível em: https:// www.sciencedirect.com/science/article/abs/pii/ S0048357512000922https://doi.org/10.1016/ j.pestbp.2012.06.005

9. Congbo Song, Lin Wu, YaochenXie, Jianjun He, Xi Chen, Ting Wang Yingchao Lin, et al. Air pollution in China: status and spatiotemporal variations. Environ.Pollut.[internet]. 2017 Ago [citado 2018 Jul 05]; 227: 334-347. Disponível em: https:// www.sciencedirect.com/science/article/pii/ S0269749116322850https://doi.org/10.1016/ j.envpol.2017.04.075

10. Domingues A. Avaliação do potencial imunotóxico do herbicida diuron: estudo de toxicidade de 28 e 90 dias (doses repetidas). [Dissertação de Mestrado], Botucatu: Faculdade de Medicina da Universidade Estadual Paulista, Brasil; 2007.

11. Sato T, Taguchi M, Nagase H,Kito H,Niikawa M. Argumentation of allergic reactions by several pesticides. Toxicology. [internet] 1998 Fev [citado 2018 Jul 05];126: 41-53. Disponível em: https:// www.ncbi.nlm.nih.gov/pubmed/9585091

12. EunHee Han, Young Pil Hwang, HyungGyun Kim, HyeGwangJ eong. Inflammatory effect of endosulfan via NF/kB activation in macrophages. Biochem. Bioph. Res. Co. [internet]. 2007 Jan [citado 2018 Jul 05]; 355: 860-865. Disponível em: https:// www.ncbi.nlm.nih.gov/pubmed/17261270 10.1016/ j.bbrc.2007.01.062

13. Sudhir Kumar, Marat Khodoun, Eric M. Kettleson, Christopher McKnight, TiinaReponen, Sergey A. Grinshpun, AtinAdhikari. Glyphosate-rich air samples induce IL-33, TSLP and generate IL-13 dependent airway inflammation. Toxicology [internet]. 2014 Ago [citado 2018 Jul 05]; 325: 42-51. Disponível em: https:// www.ncbi.nlm.nih.gov/pubmed/25172162 10.1016/j.tox.2014.08.008. 